Int. J. Environ. Sci. Tech., 3 (3): 229-242, 2006

ISSN: $1735-1472$

(C) Summer 2006, IRSEN, CEERS, IAU

\title{
Development of a master plan for industrial solid waste management
}

\author{
${ }^{1}$ M. Karamouz, ${ }^{1}$ B. Zahraie, ${ }^{1}$ R. Kerachian, ${ }^{2}$ N. Mahjouri and ${ }^{3}$ A. Moridi \\ ${ }^{1}$ Center of Excellence in Infrastructure Engineering and Management, School of Civil Engineering, \\ University of Tehran, Tehran, Iran \\ ${ }^{2}$ School of Environmental Engineering, University of Tehran, Tehran, Iran \\ ${ }^{3}$ School of Civil and Environmental Engineering, Amirkabir University, Tehran, Iran
}

Received 1 November 2005; revised 4 April 2006; accepted 25 May 2006; available online 25 June 2006

\begin{abstract}
Rapid industrial growth in the province of Khuzestan in the south west of Iran has resulted in disposal of about 1750 tons of solid waste per day. Most of these industrial solid wastes including hazardous wastes are disposed without considering environmental issues. This has contributed considerably to the pollution of the environment. This paper introduces a framework in which to develop a master plan for industrial solid waste management. There are usually different criteria for evaluating the existing solid waste pollution loads and how effective the management schemes are. A multiple criteria decision making technique, namely Analytical Hierarchy Process (AHP), is used for ranking the industrial units based on their share in solid waste related environmental pollution and determining the share of each unit in total solid waste pollution load. In this framework, a comprehensive set of direct, indirect, and supporting projects are proposed for solid waste pollution control. The proposed framework is applied for industrial solid waste management in the province of Khuzestan in Iran and a databank including GIS based maps of the study area is also developed. The results have shown that the industries located near the capital city of the province, Ahwaz, produce more than 32 percent of the total solid waste pollution load of the province. Application of the methodology also has shown that it can be effectively used for development of the master plan and management of industrial solid wastes.
\end{abstract}

Key words: Industrial solid waste management, analytical hierarchy process, multiple criteria decision making

\section{INTRODUCTION}

Disposal of industrial solid wastes which include a wide range of hazardous pollutants is one of the main environmental issues especially in the developing countries. There are a limited number of studies related to the industrial solid waste management, especially in connection with the development of a master plan for regional industrial solid waste pollution control. Roberge and Baetz, (1994) proposed a model for planning the implementation of industrial waste reduction and waste management strategies. Their model was based on minimizing the overall cost of waste reduction and waste management for an industrial facility over a specific time horizon. The optimization model was formulated as a general mixed integer linear programming problem, where the objective function included capital and operating costs and was subject to a number of constraints that defined the system under consideration. Raleigh et al., (1995) proposed a comprehensive non-hazardous

*Corresponding author, Email: karamouz@ut.ac.ir

Tel.: +9821-8855 5884; Fax: +9821-8870 1507 industrial waste classifying scheme based on the available information. This classification method was subjected to less data limitations than the previously developed models. Hogland and Stenis, (2000) had an overview of an industrial system and proposed a method of organizing an industrial waste management system. The developed model optimized the waste management policies with regard to energy, economy and environmental impacts in separate evaluations. The study included: (1) the existing system (used as a benchmark), (2) an energy-recovery system, and (3) a material-recovery system. The second system was found to be preferable with regard to energy, costs and environmental impacts. Morrissey and Browne (2004) reviewed different types of models that were being used in the area of municipal and industrial waste management and highlighted some major shortcomings of these models. Based on their research, most of the models identified in the literature were the decision support models. They showed that the shortcomings of the waste 
management models included concerns regarding the refinements of the evaluation steps rather than addressing the decision making process. In addition, while many models recognize that for a waste management model to be sustainable, it must consider environmental, economic and social aspects. None of the models examined by them, considered all three aspects together in the application. Karamouz et al., (2003) proposed a framework for developing a master plan for water resources pollution control using MCDM techniques. They proposed an integrated set of direct, indirect, and supporting water pollution control projects. Source reduction, demand management, capacity expansion, human resources development, development of monitoring and sampling network, research and technology transfer, institutional changes, and improvement of legal framework have been the major initiatives for the master plan. This research was done at Amirkabir University(Tehran Polytechnic), Tehran, Iran in 2003.

\section{MATERIALS AND METHODS}

This paper introduces a new framework in which to develop a master plan for industrial solid waste management. There are usually different criteria for evaluating the existing solid waste pollution loads and their management schemes. A multiple criteria decision making technique called AHP is used for ranking the industrial units and determining the share of each unit in the total solid waste pollution load. In this framework, a comprehensive set of direct, indirect, and supporting projects are proposed for industrial solid waste pollution control. The flowchart of the activities required for developing an industrial solid waste pollution control master plan is presented in Fig. 1. The main steps in developing a master plan for industrial solid waste management can be listed as follows:

- Data gathering: Detailed data and information, which are required for evaluating each industry, should be gathered by visiting the sites, sending questionnaires, and reviewing related reports. Data deficiencies may be tackled via engineering judgment and using experts' opinions.

- Identification of the pollution sources: Identification of the main industrial pollution sources is the first step in developing the master plan. Different criteria such as industrial solid waste quantity and quality, number of workers and water use can be used for classification of the industries into small and large units.

- Determination of the evaluation criteria: A comprehensive set of indicators should be selected for evaluating the pollution load, environmental impacts, and solid waste management in each industrial unit. Indicators can be classified to two main criteria, namely solid waste generation and management. For these criteria, some sub-criteria related to the separation, storage, transfer, and disposal of different types of domestic, nonhazardous, and hazardous industrial solid wastes can be defined.

- Determination of the share of each industry in environmental pollution through solid waste disposal: Ranking of industries based on a hierarchy structure of indicators is important for identifying the main pollution sources and the critical zones. The proposed hierarchy structure of indicators presented in Fig. 2 can be used for this purpose. The related weights of the criteria and sub-criteria in each level should be determined using a pair wise comparison. As stated by Pomerol and Barba-Romero (2000), the idea of introducing pair-wise comparisons between different criteria is to make comparisons between a pair at a time rather than assigning weights to the whole set of criteria. In order to incorporate the engineering judgments of the group of decision-makers and experts, a group decision-making method developed by Aczel and Saaty (1983) should be used. In this method, the geometric mean of each element of different pair-wise comparison matrixes is estimated. AHP which is well defined in the literature can be used for ranking of industries as well as determining their relative share of solid waste pollution, because of the nature of the problem and the hierarchy structure of the relevant criteria.

- Development of a GIS-based data bank and MIS: the gathered data should be stored in a data bank with the capabilities of statistical analysis and generation of management reports. The GIS-based maps of the study area including the location of industries, pollution loads and solid waste characteristics are for evaluating the spatial and temporal variations of the solid waste pollution loads.

- Proposing solid waste pollution control projects: The major projects of the master plan are selected and ranked based on how effective they are in reducing the environmental pollution through solid waste disposal. 


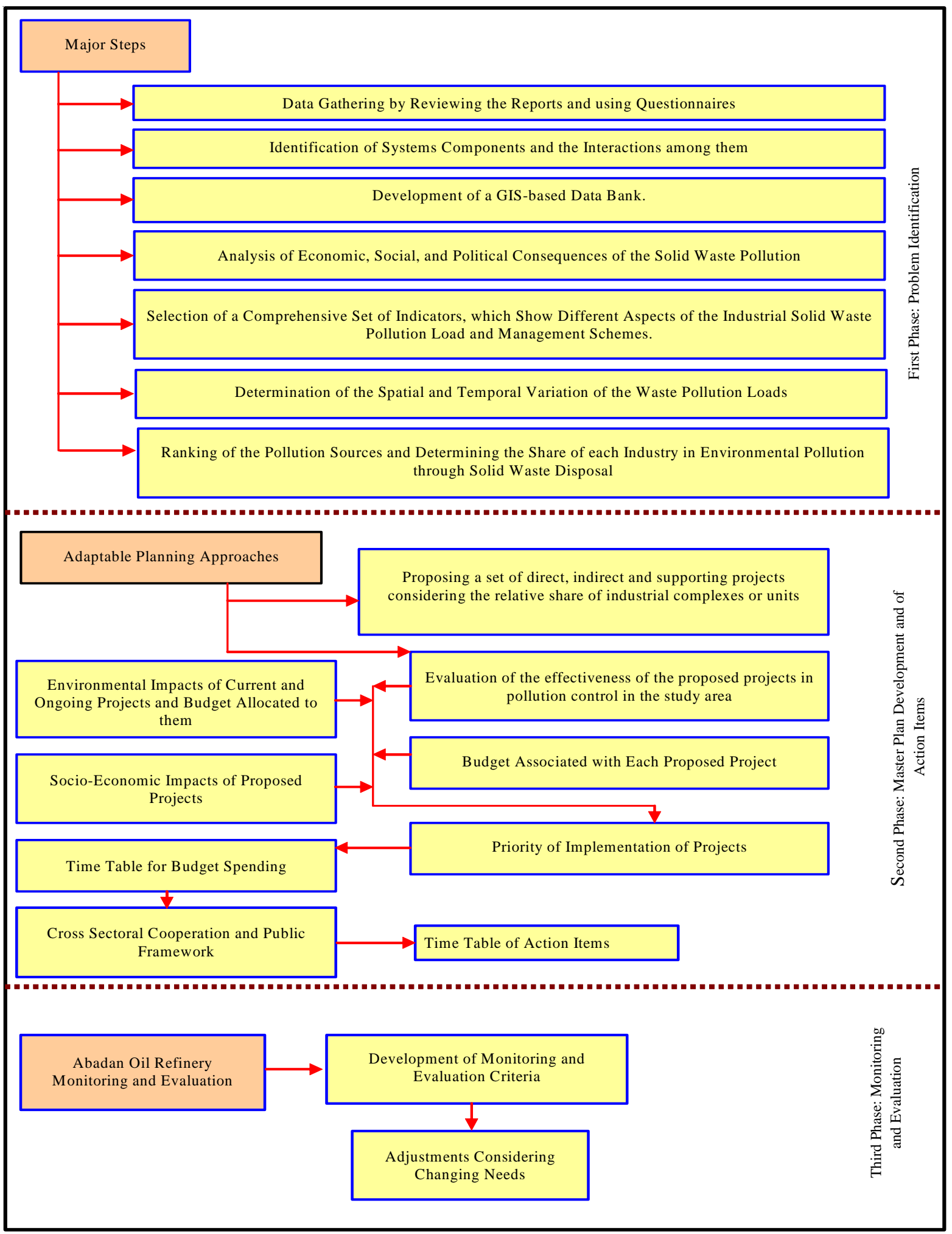

Fig. 1: The flowchart of the activities required for developing an industrial solid waste pollution control master plan (adopted from Karamouz et al., 2006) 
M. Karamouz, et al.

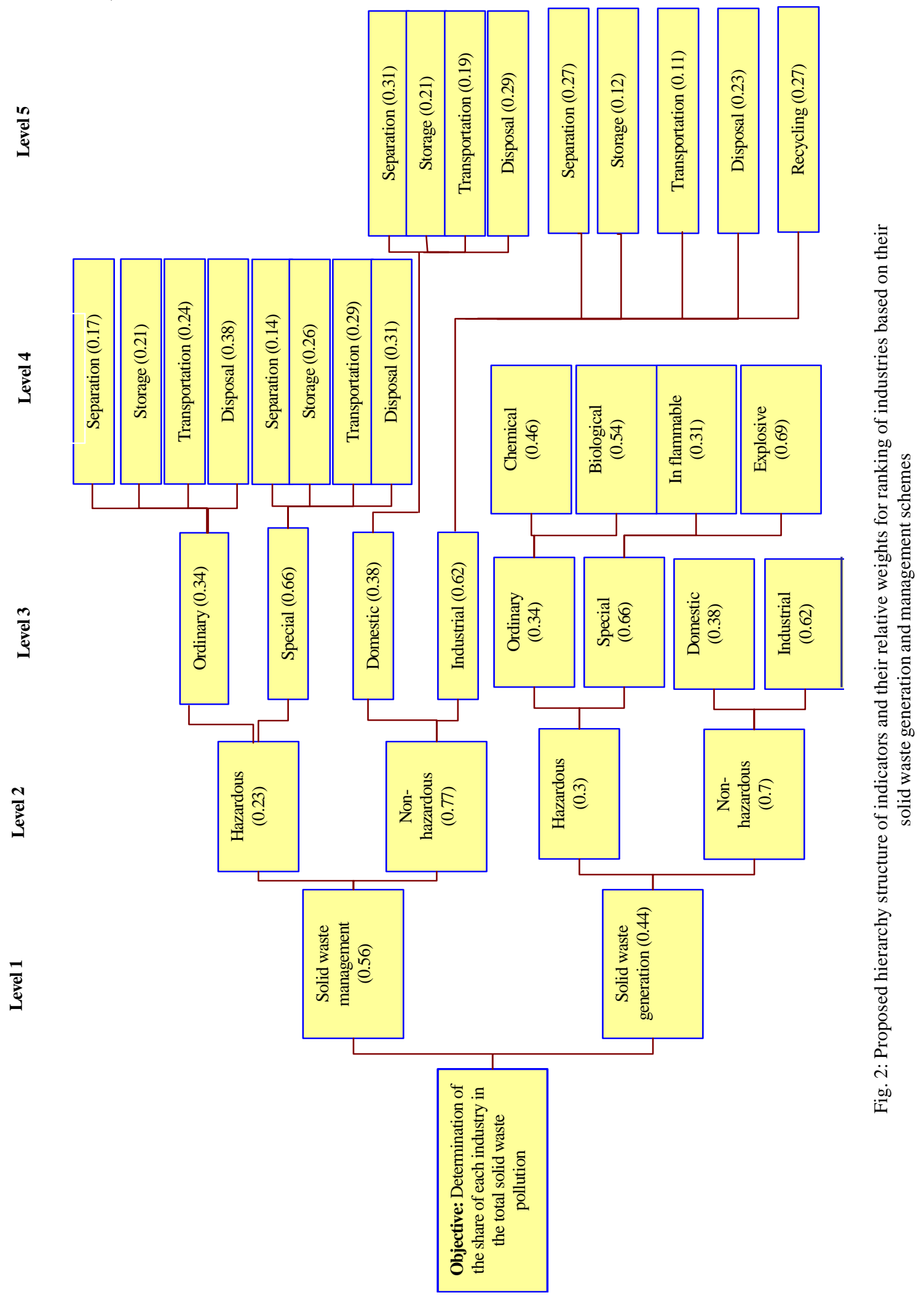




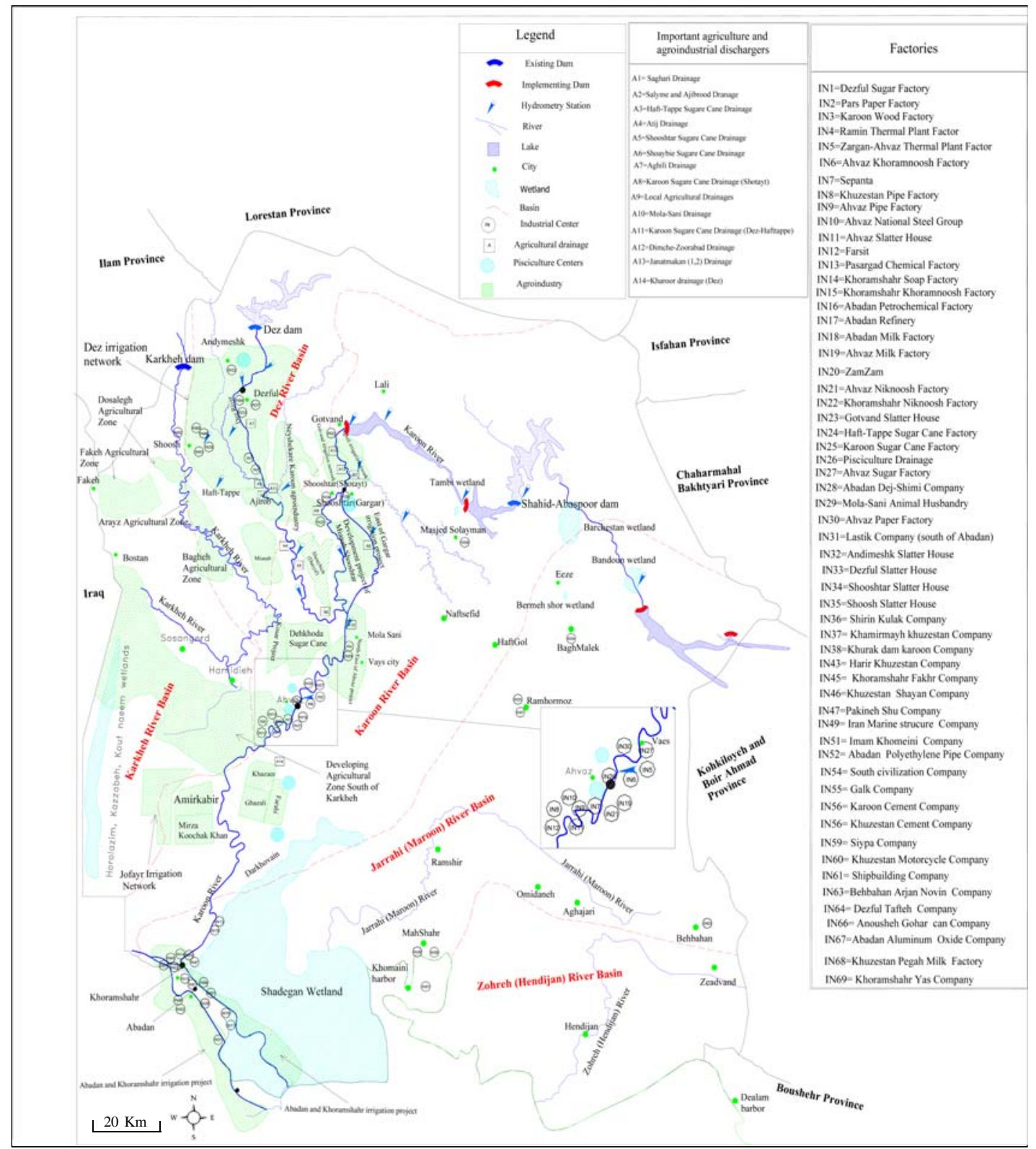

Fig. 3: The studied area and the location of the large industries

- Proposing solid waste pollution control projects: The major projects of the master plan are selected and ranked based on how effective they are in reducing the environmental pollution through solid waste disposal. The projects are usually proposed by different agencies and industries located in the study area, then they are prioritized considering their impacts on the overall master plan. Finally, the most effective projects are selected in three classes, namely, direct, indirect, and supporting projects.

Direct projects, which can directly reduce the solid waste disposal pollution load, can be categorized as follows:

- Source reduction

- Solid waste recycling and reuse

- Solid waste treatment 
- Solid waste disposal considering environmental issues Other projects, which have an indirect impact on solid waste pollution control as well as the projects aimed to improve the effectiveness of the direct and indirect projects are usually proposed as indirect and supporting projects, respectively. The supporting projects are proposed considering the following general themes:

- Integrated sampling and monitoring network

- Research and technology transfer

- Human resources capacity building and improvement of legal framework

- Monitoring and evaluation

The AHP method was first developed by Saaty (1980 and 1994) and has been widely used in both fields of theory and practice. this method is based on pair-wise comparison of the importance of different criteria and sub-criteria and the consistency of comparisons should be verified. The difference between the dominant eigenvalue, $\lambda_{\text {max }}$, and $k$ (dimension of pair-wise comparison matrix) is used by Saaty (1980 and 1994) in defining the Inconsistency Index, II:

$$
I I=\frac{\lambda_{\max }-k}{k-1}
$$

The Inconsistency ratio (IR) is then defined as:

$$
I R=I I / C R I
$$

Where, $C R I$ is the Inconsistency Index of the random matrix obtained by calculating II for randomly filled $n$ by $n$ matrix (Table 1). If $I R<10 \%$, then the consistency criterion is satisfied otherwise the decision maker should be asked to revisit the pair-wise comparisons. This procedure continues until all pair-wise comparisons satisfy the consistency criterion.

The eigenvector of pair-wise comparison matrix is then used for estimating the relative weight (importance or priority) of different alternatives. For this purpose, the following relations can be used:

$$
\begin{aligned}
& w_{i}^{a}=\sum_{j=1}^{n}\left(w_{j} \times \sum_{k=1}^{m_{i}}\left[c_{i, k} \times w_{j, k}\right]\right) \\
& w_{i}^{a}=\frac{w_{i}^{a}}{\sum_{j=1}^{m} w_{j}^{a}}
\end{aligned}
$$

Where:

$w_{i}^{a}$ : Weight of alternative (sector) $i$

$w_{i}$ : Relative weight of basic criterion $j$ which is the $j^{\text {th }}$ element of eigenvector for the pair-wise comparison matrix of basic criteria

$c_{j, k}$ : Value of sub-criterion $k$ for alternative $i$ divided by the maximum value of that sub-criterion for all alternatives

$w_{j, k}$ : Relative weight of sub-criterion $k$ of the basic criterion $j$

$w_{i}^{a}$ : Relative weight of alternative $i$

$\mathrm{m} / \mathrm{n}$ : Total number of alternatives/basic criteria

$m_{j}$ : Number of sub-criteria defined for basic criteria $i$

The selected criteria and sub-criteria for this study are shown in Fig. 2. Different large industries are considered as alternatives. The relative weight of alternative $i\left(w_{j}^{a}\right)$, which is calculated based on the proposed method can show the share of the industry $i$ in contaminating the environment through solid waste disposal.

\section{RESULTS}

The proposed methodology is applied for classification and ranking of the industrial solid waste sources and proposing a set of pollution control projects in the Khuzestan province. Khuzestan province with an area of $64236 \mathrm{~km}^{2}$ is one of the biggest provinces located in South-West of Iran. More than 4 million people are living in this province. Ahwaz, Khorramshahr, Abadan, Dezful, and Masjed Soleiman are the important cities of the Khuzestan province, with industrial activities. More than 1580 industrial units are located in this strategic province. Fig. 3 shows the location of the main cities, rivers, and large industries in the study area. Based on the classification of the Iranian Management and Planning Organization (IMPO), Khuzestan has more than 130 large industries, based on the criterion of having 50 or more personnel. Most of the Khuzestan large industries are located along the Karoon and Dez rivers with a total annual flow of 20 billion cubic meters. These rivers supply 717 million cubic meters of industrial water demand, which is 30 percent of the annual industrial water consumption in the province. The partially treated wastewaters as well as the leachate from industrial landfills are the main sources of the pollution of surface and groundwater resources in the study area. The share of industrial wastewater disposal in the pollution of the Karoon and Dez rivers is about 23 percent (Karamouz, 2002). 
Table 1: Inconsistency index of random matrixes (Saaty, 1990)

\begin{tabular}{ccccccccccc}
\hline$n$ & 1 & 2 & 3 & 4 & 5 & 6 & 7 & 8 & 9 & 10 \\
\hline CRI & 0 & 0 & 0.58 & 0.9 & 1.12 & 1.24 & 1.32 & 1.41 & 1.45 & 1.45 \\
\hline$n$ : dimension of random matrix & & & & & &
\end{tabular}

The total annual solid waste in the study area is about 634,000 tons; in which industries have a significant contribution in generating such a high amount of solid wastes. In this study, by revising an existing questionnaire of the Iranian Department of the Environment (DOE), a more comprehensive questionnaire was designed for gathering the basic data related to the main characteristics of industrial solid wastes and their disposal in the study area. The main criteria proposed for the industrial solid waste classification as appeared in the American Resource Conservation Recovery Act (ARCRA) are considered in developing the new questionnaire. The questionnaires were filled up by evaluating the qualitative and quantitative characteristics of the solid wastes as well as the processes utilized for separation, packing, transportation, incineration, and disposal of the hazardous and non-hazardous wastes in each industrial unit. Some additional data such as the number of staff and workers, water use, wastewater flow rate, and the method of wastewater treatment are also gathered. This information can present the composition of the industrial solid wastes such as the relative weigh of the domestic, non-hazardous, hazardous (toxic, biological, inflammable, corrosive, and explosive) wastes in each industry as well as the province. The results show that 98 percent of the total weight of the industrial solid wastes is due to the waste disposal from steel industries located in the study area. For ranking the industries based on their solid waste generation and management practices as well as determining the spatial distribution of the industrial solid waste pollution in the study area, a hierarchy structure of indicators is proposed (Fig. 2). As it is shown in this fig., in the first level of the structure, there are two main criteria for evaluating the solid waste generation and management. These two criteria are evaluated based on the characteristics of the hazardous and non-hazardous industrial solid wastes. In this structure, some sub-criteria such as separation, storage, transportation, and disposal of different types of industrial solid wastes are used which are related to the solid waste management criterion. The relative weights of the criteria are calculated based on pair- wise comparisons set by the decision-makers and experts familiar with the system. These comparisons are usually presented in form of pair-wise comparison matrices. Decision-makers can assign a consistent weight when only two criteria are involved; however when there are several criteria, the weighting and judgments about their importance in environmental polluting through solid waste disposal are rather difficult and could result in inconsistent assessments. The geometric mean method is used in this study to find the group judgment about the relative importance of sub-indicators, which resulted in the weights shown in Fig. 2.

As an example, the following matrix shows the group judgments for the sub-criteria of the non-hazardous solid waste:

\begin{tabular}{|c|c|c|c|c|c|}
\hline & $S$ & ST & $\mathrm{T}$ & D & $\mathrm{R}$ \\
\hline Seperation (s) & 1 & 2.3 & 2.45 & 1.17 & 1 \\
\hline Storage (ST) & 0.43 & 1 & 1 & 2 & 2.5 \\
\hline Transportation (T) & 0.4 & 1 & 1 & 2 & 2.5 \\
\hline Disposal (D) & 0.85 & 0.5 & 0.5 & 1 & 1 \\
\hline Recycling (R) & 1 & 0.4 & 0.4 & 1 & 1 \\
\hline
\end{tabular}

As it can be seen in this matrix, the group judgments are inconsistent. For example, the relative importance of separation compared with storage is 2.3 and the relative importance of storage compared with transportation is 1 . If the decision-makers comparisons were consistent, the relative importance of separation compared with transportation would be $2.3 \times 1=2.3$ but the decision maker indicated it as 2.45 . Therefore, the matrix looks inconsistent. In this study, the inconsistency of pair-wise comparison matrices is quantified using the inconsistency index for the pairwise comparison matrix of the basic criteria $\left(\mathrm{II}_{b}\right) . \mathrm{II}_{b}$ for the above matrix is equal to 0.001 which is less than 0.1 , so it is considered to be consistent. As the number of industries is more than 9, application of ordinary AHP method will be limited as Saaty (1990) suggested. Therefore, the value of the indicators located in the third level of the hierarchy structure is clustered into 7 classes considering their range of variations. Table 2 presents the characteristics of the selected classes for ranking the large industries located in the Province of 
Khuzestan. The total score (grade) of each industry is calculated by summation of a partial grade $(P G)$ related to each criterion located in the last level of hierarchy structures. $P G$ is calculated as follows:

$$
P G=\frac{{ }^{w_{I n d}}{ }^{*}{ }^{w_{I}}}{{ }^{w_{I_{M A X}}}}
$$

where:

$\mathrm{w}_{\mathrm{I}}$ : Weight of the interval $I$ that the evaluator score falls into

$\mathrm{w}_{\text {Ind }}$ : Weight of the indicator in the last level (Fig. 2), which is the relative importance of the indicator compared to the others.

$w_{I_{\text {MAX }}}$ : The maximum weight of the intervals related to the corresponding criterion

The relative weight of each industry (its share in environmental pollution through solid waste disposal) is calculated for each alternative (industry) by the summation of partial grades of the indicators located in the last level and the final ranking is obtained.

The overall inconsistency index $(\overline{I I})$ is estimated by combining the inconsistency index of basic criteria and the effects of sub-criteria as follows:

$$
\begin{aligned}
& \overline{I I}=I I_{a}+\left[\begin{array}{ll}
0.56 & 0.44
\end{array}\right]\left[\begin{array}{l}
I I_{b} \\
I I_{c}
\end{array}\right]+\left[\begin{array}{ll}
0.23 & 0.77
\end{array}\right]\left[\begin{array}{l}
I I_{e} \\
I I_{f}
\end{array}\right] \\
& +\left[\begin{array}{ll}
0.3 & 0.7
\end{array}\right]\left[\begin{array}{l}
I I_{g} \\
I I_{h}
\end{array}\right]+\left[\begin{array}{ll}
0.34 & 0.66
\end{array}\right]\left[\begin{array}{l}
I I_{i} \\
I I_{k}
\end{array}\right]+ \\
& {\left[\begin{array}{ll}
0.38 & 0.62
\end{array}\right]\left[\begin{array}{l}
I I_{m} \\
I I_{n}
\end{array}\right]+\left[\begin{array}{ll}
0.35 & 0.65
\end{array}\right]\left[\begin{array}{l}
I I_{p} \\
I I_{q}
\end{array}\right]}
\end{aligned}
$$

Where:

$I I_{a}$ : Inconsistency index of the pair-wise comparison matrix of the basic criteria located in level 1.

$I I_{b}, I I_{c}$ : inconsistency indices of the pair-wise comparison matrices of the indicators located in level 2, which are related to the Solid Waste Generation and Solid Waste Management criteria, respectively.

$I I_{e}, I I_{f}, I I_{q}, I I_{h}$ : inconsistency indices of the pair wise comparison matrices of the indicators located in level 3.
$I I_{i}, I I_{k}, I I_{m}, I I_{n}, I I_{p}, I I_{q}:$ inconsistency indices of the pair wise comparison matrices of the indicators located in level 4.

The overall random inconsistency index of the hierarchy structure $\overline{C R I}$ is then estimated similar to $\overline{I I}$, but in equation $6, I_{i}$, which is the inconsistency index of matrix $i$, is replaced with $C R I_{n}$. CRI $I_{n}$ is the inconsistency index of a $n \times n$ random matrix and $n$ is the dimension of the pair-wise comparison matrix. Therefore, considering the value of the inconsistency index of the random matrices presented in Table $1, \overline{C R I}$ can be calculated as:

$$
\begin{aligned}
& \overline{C R I}=C R I_{2}+\left[\begin{array}{ll}
0.56 & 0.44
\end{array}\right]\left[\begin{array}{l}
C R I_{2} \\
C R I_{2}
\end{array}\right] \\
& +\left[\begin{array}{ll}
0.23 & 0.77
\end{array}\right]\left[\begin{array}{l}
C R I_{2} \\
C R I_{2}
\end{array}\right]+\left[\begin{array}{ll}
0.3 & 0.7
\end{array}\right]\left[\begin{array}{l}
C R I_{2} \\
C R I_{2}
\end{array}\right]+ \\
& {\left[\begin{array}{ll}
0.34 & 0.66
\end{array}\right]\left[\begin{array}{l}
C R I_{4} \\
C R I_{5}
\end{array}\right]+\left[\begin{array}{ll}
0.38 & 0.62
\end{array}\right]\left[\begin{array}{l}
C R I_{4} \\
C R I_{4}
\end{array}\right]} \\
& +\left[\begin{array}{ll}
0.35 & 0.65
\end{array}\right]\left[\begin{array}{l}
C R I_{2} \\
C R I_{2}
\end{array}\right]=0+0+\left[\begin{array}{ll}
0.34 & 0.66
\end{array}\right]\left[\begin{array}{l}
0.9 \\
0.9
\end{array}\right] \\
& +\left[\begin{array}{ll}
0.38 & 0.62
\end{array}\right]\left[\begin{array}{l}
0.9 \\
1.12
\end{array}\right]+0=1.94
\end{aligned}
$$

The overall IR is then estimated using Equation 2 as 0.04 , which is less than 10 percent. Therefore, the group judgments in matrices are used for estimating the share of different industries in pollution of the system due to waste disposal. Table 3 presents the main characteristics of solid waste generation and management in different industries in the Khuzestan province. Tables 4 and 5 present the shares of contamination for different industrial zones as well as different industries, which are estimated using Equations 4 and 5. As it can be seen in Table 5, the Ahwaz region produces the highest load of industrial solid waste disposal. Table 6 presents the share of industries considering different relative weights for solid waste generation and management. As it can be seen in this table, the share of each industry in polluting the environment is not considerably dependent on the relative weight of the criteria. Therefore, the calculated share of industries in polluting the environment can be properly used in developing the master plan. 
Development of a master...

Table 2: Clustering of the annual weight of disposed industrial solid wastes in the province of Khuzestan (t/y)

\begin{tabular}{cllllcc}
\hline \multirow{2}{*}{ Cluster \# } & & \multicolumn{5}{c}{ Type of industrial solid waste } \\
& Domestic & Non-hazardous & Chemical $^{*}$ & Biological & Inflammable & Explosive \\
\hline 1 & $0-15$ & $0-19$ & $0-10$ & $0-10$ & $0-1.5$ & 0 \\
2 & $16-51$ & $20-400$ & $11-40$ & $11-180$ & $1-6-150$ & $>0$ \\
3 & $52-190$ & $401-990$ & $41-300$ & $181-500$ & $151-250$ & - \\
4 & $191-350$ & $991-3000$ & $301-2000$ & $501-2100$ & $251-550$ & - \\
5 & $351-361$ & $3001-9000$ & $2001-15000$ & - & - & - \\
6 & $362-750$ & $9001-15000$ & $15001-38000$ & - & - & - \\
7 & $751-1110$ & - & - & - & - & - \\
\hline
\end{tabular}

${ }^{*}$ Including toxic and corrosive wastes

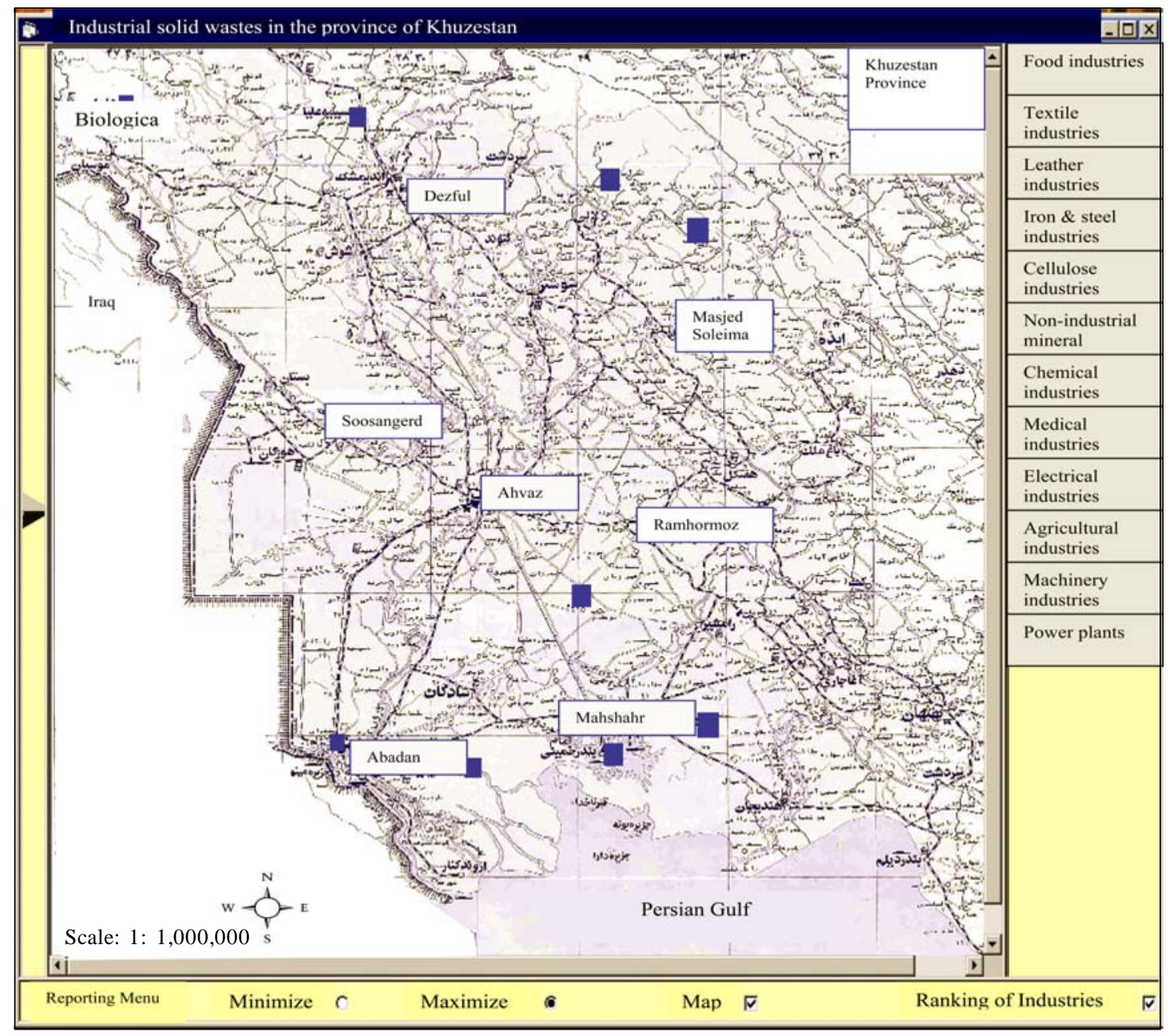

Fig. 4: The main menu of Khuzestan solid waste management information system 
M. Karamouz, et al.

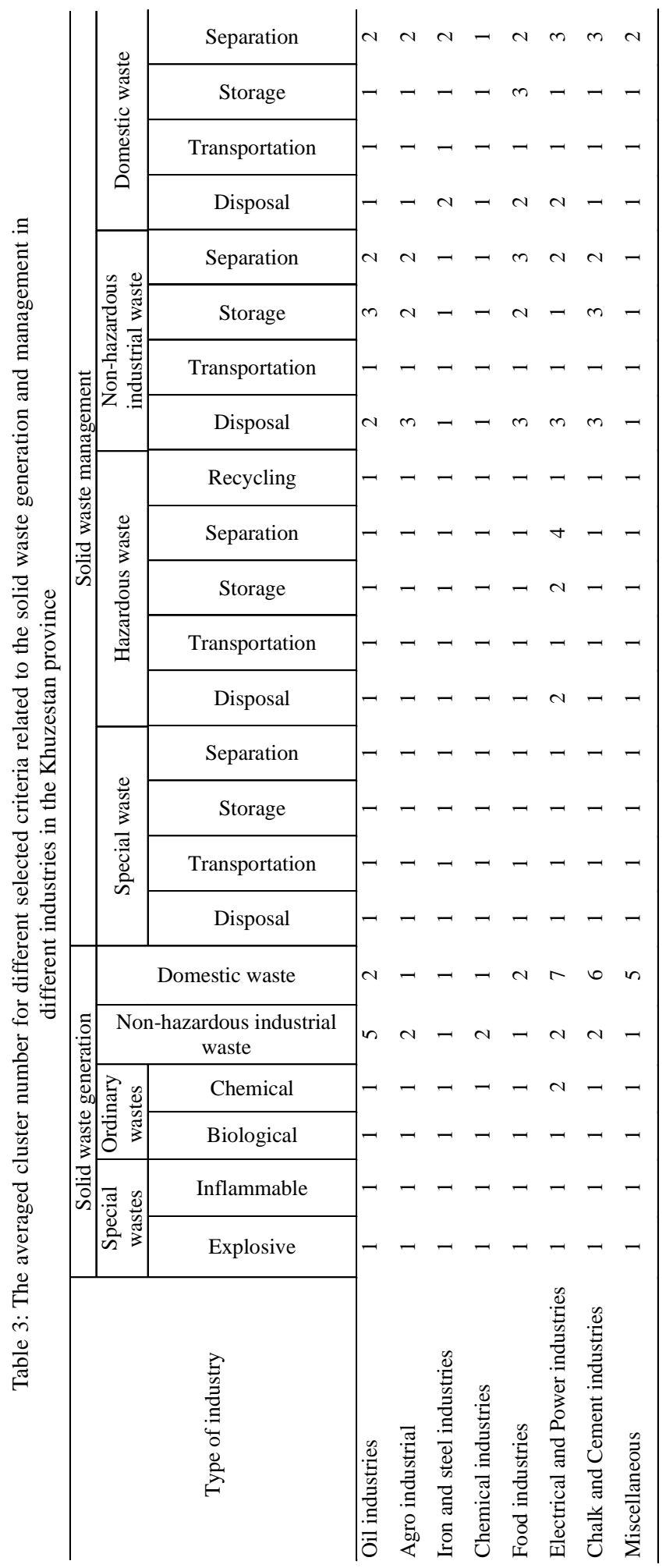




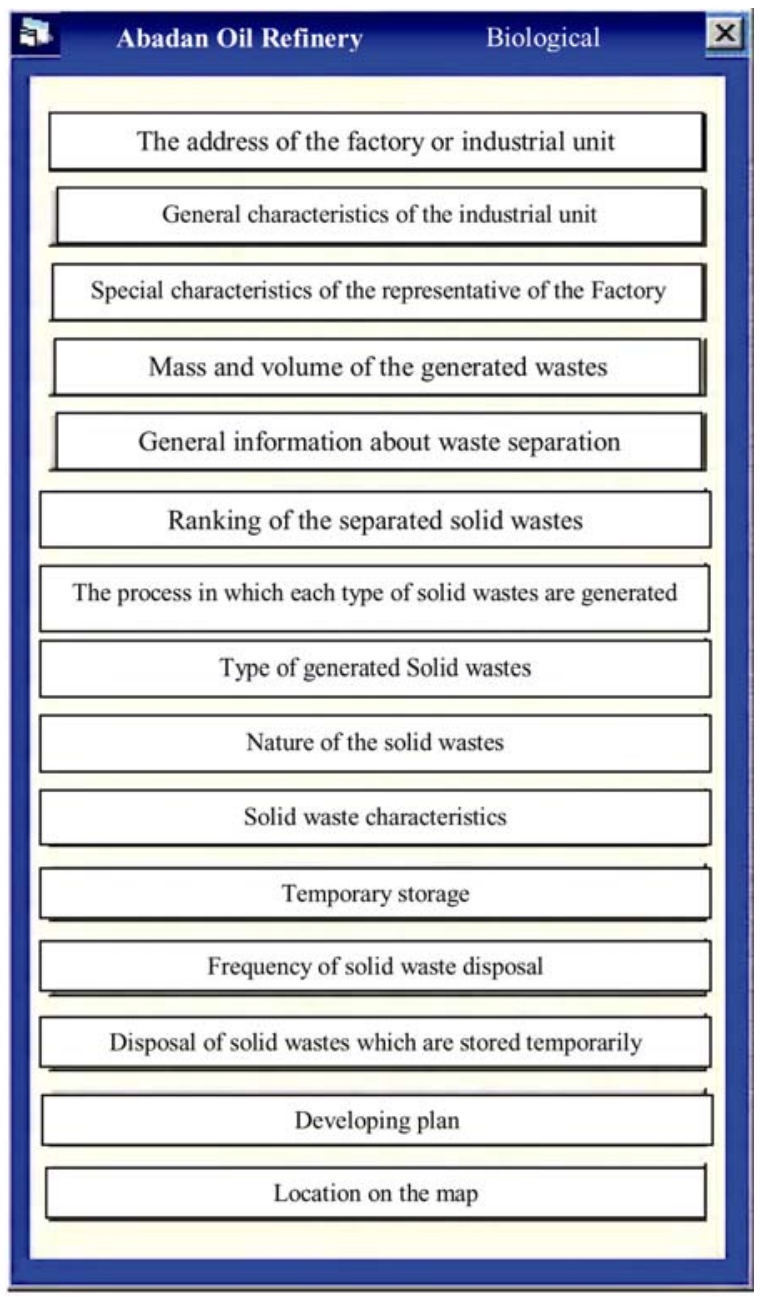

Fig. 5: The main data retrieval menu for each industry

\section{DISCUSSION AND CONCLUSION}

The main objective of this master plan is to comply with the regulations developed by the IDE during a 2year time horizon in processes such as industrial solid waste separation, storage, transportation, and disposal. It is assumed that all existing and implementing industrial projects such as the second phase of Abadan refinery will satisfy the existing guidelines and standards and their environmental impacts due to solid waste disposal are not considered in this study. The major projects of the master plan are selected and ranked based on how effective they are in reducing the environmental impacts through solid waste disposal in the study area. The projects are initially proposed by different industries, then, they are prioritized considering their impact toward the objective of this study. Finally, the most effective projects are selected as follows:

- Equipping all industries in the study with industrial solid wastes collection, separation, and storage systems based on the IDE standards and the guidelines proposed in this master plan

- Equipping industries for transportation of the industrial solid wastes

- Improving the production processes of some industries to reduce the value of the generated solid wastes and produce the solid wastes, which are recyclable

- Disposing the domestic solid waste generated in the industries in municipal landfills

- Developing a comprehensive MIS for industrial solid waste generation and management in the studied area.

- Proposing and implementing the research projects related to the industrial solid waste recycling.

- Developing local regulations and guidelines for industrial solid waste collection, separation, storage, transportation, and disposal considering the existing national regulations

Table 5: Share of contamination of solid waste disposal of the top10 polluting industries in the province of Khuzestan (\%)

\begin{tabular}{cll}
\hline Rank & \multicolumn{1}{c}{ Region (City) } & Share (\%) \\
\hline 1 & Imam Khomeini Port & 14.6 \\
2 & Ahwaz & 11.9 \\
3 & Abadan & 7.2 \\
4 & Ahwaz & 4.98 \\
5 & Ahwaz & 4.86 \\
6 & Shoosh & 3.3 \\
7 & Shooshtar & 3.3 \\
8 & Ahwaz & 2.96 \\
9 & Ahwaz & 2.836 \\
10 & Ahwaz & 2.7 \\
\hline
\end{tabular}

Table 4: Share of contamination of solid waste disposal of the industries located in different regions in the province of Khuzestan (\%)

\begin{tabular}{cllllc}
\hline Rank & Region (City) & Share (\%) & Rank & Region (City) & Share (\%) \\
\hline 1 & Ahwaz & 32.1 & 6 & Khorramshahr & 5.2 \\
2 & Abadan & 19 & 7 & Dezful & 4.4 \\
3 & Shooshtar & 16.9 & 8 & Imam Khomeini Port & 1.8 \\
4 & Shoosh & 10.5 & 9 & Ramhormoz & 1.6 \\
5 & Behbahan & 7.2 & 10 & Haft tappeh & 1.3 \\
\hline
\end{tabular}




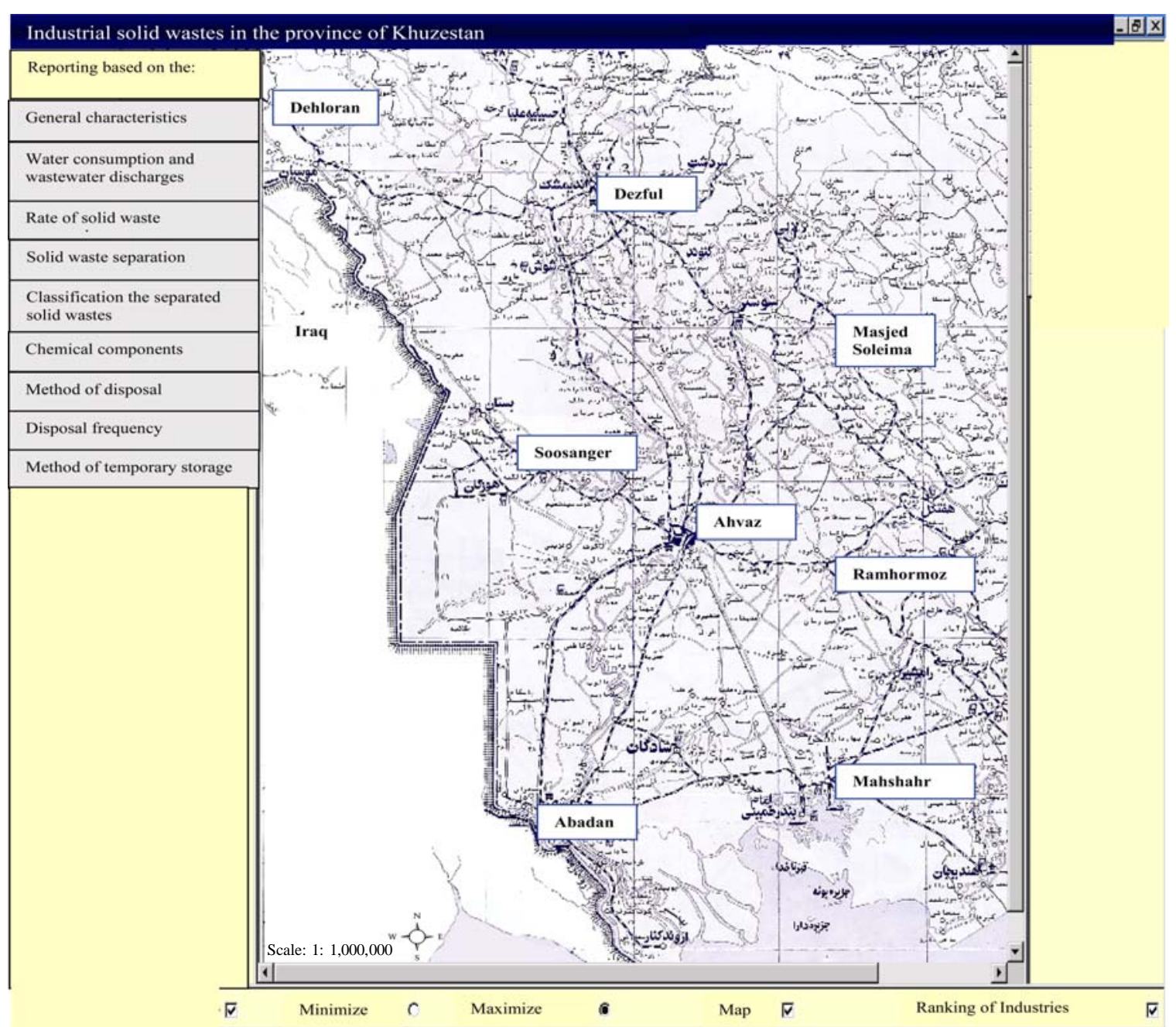

Fig. 6: The main menu of data and information report generation

Table 6: Share of industries in environmental polluting considering different weights for solid waste generation and management

\begin{tabular}{lccccc}
\hline \multicolumn{1}{c}{ Type of Industry } & WSM: 0.36, & WSM: 0.46, & WSM: 0.56, & WSM: 0.66, & WSM 0.76, \\
& WSP: 0.64 & WSP: 0.54 & WSP: 0.44 & WSP: 0.34 & WSP: 0.24 \\
\hline Oil industries & 15.5 & 16 & 15.9 & 16.7 & 17.2 \\
Agro industries & 32.1 & 31.5 & 30.5 & 30.3 & 29.9 \\
Iron and steel industries & 18.4 & 16.4 & 15.3 & 12.7 & 10.8 \\
Chemical industries & 1.4 & 1.7 & 2 & 2.3 & 2.6 \\
Food industries & 14.1 & 16.2 & 18.5 & 20.5 & 22.5 \\
Electrical and power industries & 11.4 & 10.2 & 9 & 7.8 & 6.6 \\
Chalk and cement industries & 3.4 & 4 & 4.5 & 5.1 & 5.5 \\
Miscellaneous & 3.7 & 4 & 4.3 & 4.6 & 4.9 \\
Sum & $\mathbf{1 0 0}$ & $\mathbf{1 0 0}$ & $\mathbf{1 0 0}$ & $\mathbf{1 0 0}$ & $\mathbf{1 0 0}$ \\
\hline
\end{tabular}

WSM: weight of solid waste management

WSP: weight of solid waste production 
- Developing the human resources for solid waste recycling in industries

- Training the staff of the solid waste management systems in different industrial units

- Monitoring and evaluation of the solid waste management systems in the industries

The effectiveness of the proposed projects is evaluated using the hierarchical structure of the criteria and their relative weights, calculated in this study (Fig. 2).

As mentioned before, the collected data should be stored in a data bank with the capabilities of statistical analysis and generating management reports. In this study, a data bank and GIS-based maps of the study area has been developed. The main menu of this system is shown in Fig. 4. This Fig. represents a map of the province of Khuzestan including the main industries. The main categories of the industries are shown in the right hand side of the map. By selecting each category, the main related industries are appeared in the province map. By clicking on each industry, some information related to the selected industry such as solid waste quantity and quality, solid waste separation, storage, transportation, and disposal are presented (Fig. 5). In order to generate reports, a menu has been developed (Fig. 6). The Reports include all data, which has been stored in the data bank. In this paper, different aspects of development of a master plan in industrial solid waste pollution reduction are discussed. Definition of objectives, system identification and action items as well as the projects needed for pollution reduction are considered and described in the context of a case study for Khuzestan Province in Iran. In order to estimate the effects of different industries as well as industrial zones on the environmental pollution in the study area, a MCDM technique, namely the AHP method is used. Subjective information about relative importance of different criteria is also incorporated in this analysis. The inconsistency in engineering judgments were also assessed and incorporated in finding the relative importance of different water quality indicators by utilizing the AHP method. An economic analysis can also be used instead of the proposed AHP based method considering the cost associated with the environmental impacts of the pollution load of different industries and how cost effective the waste pollution control projects are. The economic-based methods, especially in the developing countries, suffer from data deficiencies and uncertainties in inflation and interest rates over the long- term planning horizon. The proposed MCDM method can easily incorporate the available limited data, experts' opinions, and engineering judgments in defining the criteria and their relative weights in many developing countries in which the economic data is not usually available. The main objective of the master plan for the study area has been to comply with the existing regulations and standards in a 2 year time horizon. Pollution load reduction, development of industrial solid waste separation, storage, transportation and disposal systems, human resources development, development of monitoring and sampling networks, research and technology transfer, institutional changes and improvement of the legal framework have been the major proposed projects for the master plan. Subjective information as well as engineering judgment has been used to overcome the data deficiencies for this type of analysis. Breakdown of the total percentage of waste pollution generated through the activities of different industries, the cost associated with different projects, and the estimated rate of pollution reduction by different projects have been determined. The total budget needed for improving the environmental problems of industrial solid wastes in the Ahwaz region in a 2 year time horizon is estimated as 13.967 Billion Iranian Rials (1.552 Million Dollars). The variation of budget depends on an estimate of the process of approval, construction period, and the waiting period for the full operation. Most of the required budget should be expended during the first two years after implementing the master plan.

The results of application of the proposed framework in the province of Khuzestan show that this methodology can be effectively used for development of a master plan for industrial solid waste pollution control.

\section{ACKNOWLEDGMENTS}

This study was partially funded by the Khuzestan Department of the Environment. Contribution of managers and engineers of this Department is hereby acknowledged.

\section{Notations}

The following symbols are used in this paper:

$\lambda=$ Eigen value of pair-wise comparison matrix

$\lambda_{\max }=$ Dominant eigenvalue

$A=$ Pair-wise comparison matrix

$C_{i j}=$ Value of criterion $\mathrm{i}$ for alternative $\mathrm{j}$ 
$a_{i j}=$ Elements of pair-wise comparison matrix

$C R l=$ Inconsistency index for randomly filled matrixes with dimension $n$

II = Inconsistency Index

$I_{h}=$ Inconsistency index for basic criteria

$I R=$ Inconsistency Ratio

$m_{1}, \cdots, m_{n}=$ index of sub-criteria

$N$ = umber of decision-makers

$r_{i j}=$ Elements of row $i$ and column $j$ in the

dimensionless decision matrix

$w=$ Eigen vector of pair-wise comparison matrix

$w_{i}^{a}=$ Weight of alternative $i$

$w_{i}=$ Weight of alternative $i$

$w_{i}^{a}=$ Relative weight of alternative $i$

$W_{I_{\text {MAX }}}$ : The maximum weight of the intervals related to the corresponding criterion

\section{REFERENCES}

Aczel, J. and Saaty, T., (1983). Procedure for synthesizing ratio judgments. J.Math. Psyco., 27, 93-102.

Hogland, W. and Stenis, J., (2000). Assessment and system analysis of industrial waste management. Waste Manag., 2 (7), 537-543.

Karamouz, M., Zahraie, B. and Kerachian, R., (2003).

Development of a master plan for water pollution control using MCDM techniques: a case study. J.Wat. Int., 28 (4), 478-490.

Karamouz, M., (2002). Development of a master plan for pollution control of Karoon River in Iran. Technical Report, Khuzestan the School of Environmental Engineering, Ahvaz, Iran.

Karamouz, M., (2003). Identification and classification of the solid wastes of large industries in the province of Khuzestan, Iran. Technical Report, Khuzestan Department of the Environment, Ahvaz, Iran.

Karamouz, M., Zahraie, B., Kerachian, R., Jaafarzadeh, N. and Mahjuri, N., (2006). Developing amaster plan for hospital solid waste management: Acase study, Waste Manag., 26 (in press).

Morrissey, J. and Browne, J., (2004). Waste management models and their application to sustainable waste management. Waste Manag., 24 (3), 297-308.

Pomerol, J. C. and Barba-Romero, S., (2000). Multicriterion decision in management: principles and practice, Kluwer Academic Publishers.

Roberge, H. D. and Baetz, B. W., (1994). Optimization modeling for industrial waste reduction planning, Waste Manag., 14 (1), 35-48.

Raleigh, L. H., Knox, R. C. and Canter, L. W., (1995). Proposed non-hazardous industrial-waste classification scheme. J. Environ. Eng., ASCE., 121 (5), 402-410.

Saaty, T. L., (1980). The analytical hierarchy process, planning, priority, resource allocation. RWS Publication, USA.

Saaty, T. L., (1990). The analytical hierarchy process, McGraw-Hill, New York.

Saaty, T. L., (1994). Highlights and critical points in the theory and application of the analytical hierarchy process. Europ. J. Operat. Res., 74, 426-447.

\section{AUTHOR(S) BIOSKETCHES}

Karamouz, M., Ph.D. is a professor at the School of Civil Engineering, University of Tehran, Tehran, Iran, Email: karamouz@ut.ac.ir

Zahraie, B., Ph.D. is an assistant professor at the School of Civil Engineering, University of Tehran, Tehran, Iran, Email: bzahraie@ut.ac.ir

Kerachian, R., Ph.D. is an assistant professor at the School of Civil Engineering, University of Tehran, Tehran, Iran, Email: kerachian@ut.ac.ir

Mahjouri, N., is a Ph.D. Student at the Department of Environment, University of Tehran, Tehran, Iran, E-mail: mahjouri@ut.ac.ir

Moridi, A., is a Ph.D. candidate at the School of Civil and Environmental Engineering, Amirkabir University, Tehran, Iran, Email:moridi@aut.ac.ir

This article should be referenced as follows:

Karamouz, M., Zahraie, B., Kerachian, R., Mahjouri, N., and Moridi, A., (2006). Development of

a master plan for industrial solid waste management. Int. J. Environ. Sci. Tech., 3 (3), 229-242. 